\title{
BMJ Open Patient-reported outcome measures following revision knee replacement: a review of PROM instrument utilisation and measurement properties using the COSMIN checklist
}

Shiraz A Sabah (D), Elizabeth A Hedge, Simon G F Abram (1) , Abtin Alvand, Andrew J Price, Sally Hopewell

To cite: Sabah SA, Hedge EA, Abram SGF, et al. Patientreported outcome measures following revision knee replacement: a review of PROM instrument utilisation and measurement properties using the COSMIN checklist. BMJ Open

2021;11:e046169. doi:10.1136/ bmjopen-2020-046169

- Prepublication history and additional supplemental material for this paper are available online. To view these files, please visit the journal online (http://dx.doi.org/10.1136/ bmjopen-2020-046169)

Received 21 0ctober 2020 Accepted 24 August 2021

Check for updates

(c) Author(s) (or their employer(s)) 2021. Re-use permitted under CC BY-NC. No commercial re-use. See rights and permissions. Published by BMJ.

Nuffield Department of Orthopaedics, Rheumatology and Musculoskeletal Sciences, University of Oxford, Oxford, UK

Correspondence to

Shiraz A. Sabah;

shiraz.sabah@ndorms.ox.ac. uk and

Shiraz A Sabah;

shiraz.sabah@ndorms.ox.ac.uk

\section{ABSTRACT}

Objectives To identify: (1) patient-reported outcome measures (PROMs) used to evaluate symptoms, health status or quality of life following discretionary revision (or re-revision) knee joint replacement, and (2) validated jointspecific PROMs, their measurement properties and quality of evidence.

Design (1) Scoping review; (2) systematic review following the COnsensus-based Standards for selection of health status Measurement INstruments (COSMIN) checklist.

Data sources MEDLINE, Embase, AMED and PsycINF0 were searched from inception to 1 July 2020 using the Oxford PROM filter unlimited by publication date or language.

Eligibility criteria for selecting studies Studies reporting on the development, validation or outcome of a joint-specific PROM for revision knee joint replacement were included.

Results 51 studies reported PROM outcomes using eight joint-specific PROMs. 27 out of 51 studies (52.9\%) were published within the last 5 years. PROM development was rated 'inadequate' for each of the eight PROMs studied. Validation studies were available for only three jointspecific PROMs: Knee Injury and Osteoarthritis Outcome Score (KO0S), Lower Extremity Activity Scale (LEAS) and Western Ontario and McMaster Universities Arthritis Index (WOMAC). 25 out of 27 (92.6\%) measurement properties were rated insufficient, indeterminate or not assessed. The quality of supporting evidence was mostly low or very low. Each of the validated PROMs was rated 'B' (potential for recommendation but require further evaluation).

Conclusion Joint-specific PROMs are increasingly used to report outcomes following revision knee joint replacement, but these instruments have insufficient evidence for their validity. Future research should be directed toward understanding the measurement properties of these instruments in order to inform clinical trials and observational studies evaluating the outcomes from joint-specific PROMs.

\section{INTRODUCTION}

Primary knee replacement is a successful procedure that improves quality of life for
Strengths and limitations of this study

- This is the first study to apply the Consensus-based Standards for the selection of health Measurement INstruments (COSMIN) checklist to report the quality of patient-reported outcome measure (PROM) development and validation studies for discretionary revision knee joint replacement.

- Our search strategy was based on the Oxford PROM filter, which has been shown to be a sensitive tool for identifying relevant studies.

- PROM instruments that were not patient completed were excluded, which maintained a patient-focus, but limited the number of eligible instruments for evaluation.

- While our study has critically summarised PROM measurement properties, qualitative studies may be needed in the future to provide deeper insights into the outcomes from revision knee replacement that are most important to patients.

the majority of patients by reducing pain and improving joint function. ${ }^{1}$ However, not all patients achieve a good outcome. For example, approximately $13 \%$ of patients are dissatisfied with their outcome following knee replacement, ${ }^{2}$ with higher rates in younger patients ${ }^{3}$ and those with partial thickness cartilage loss. ${ }^{4}$ Many of these patients are managed with supportive treatment. ${ }^{5}$ However, at 10 years following primary knee replacement, $3.5 \%$ of patients will have undergone revision surgery. In total, 6500 revision knee replacement procedures are performed each year in the UK. ${ }^{6}$ The majority of these procedures $(\sim 85 \%)$ are for discretionary indications, where the goal of surgery is to improve joint function and quality of life. ${ }^{6}$ These contrast to non-discretionary procedures (such as for infection or fracture), which are necessary to 


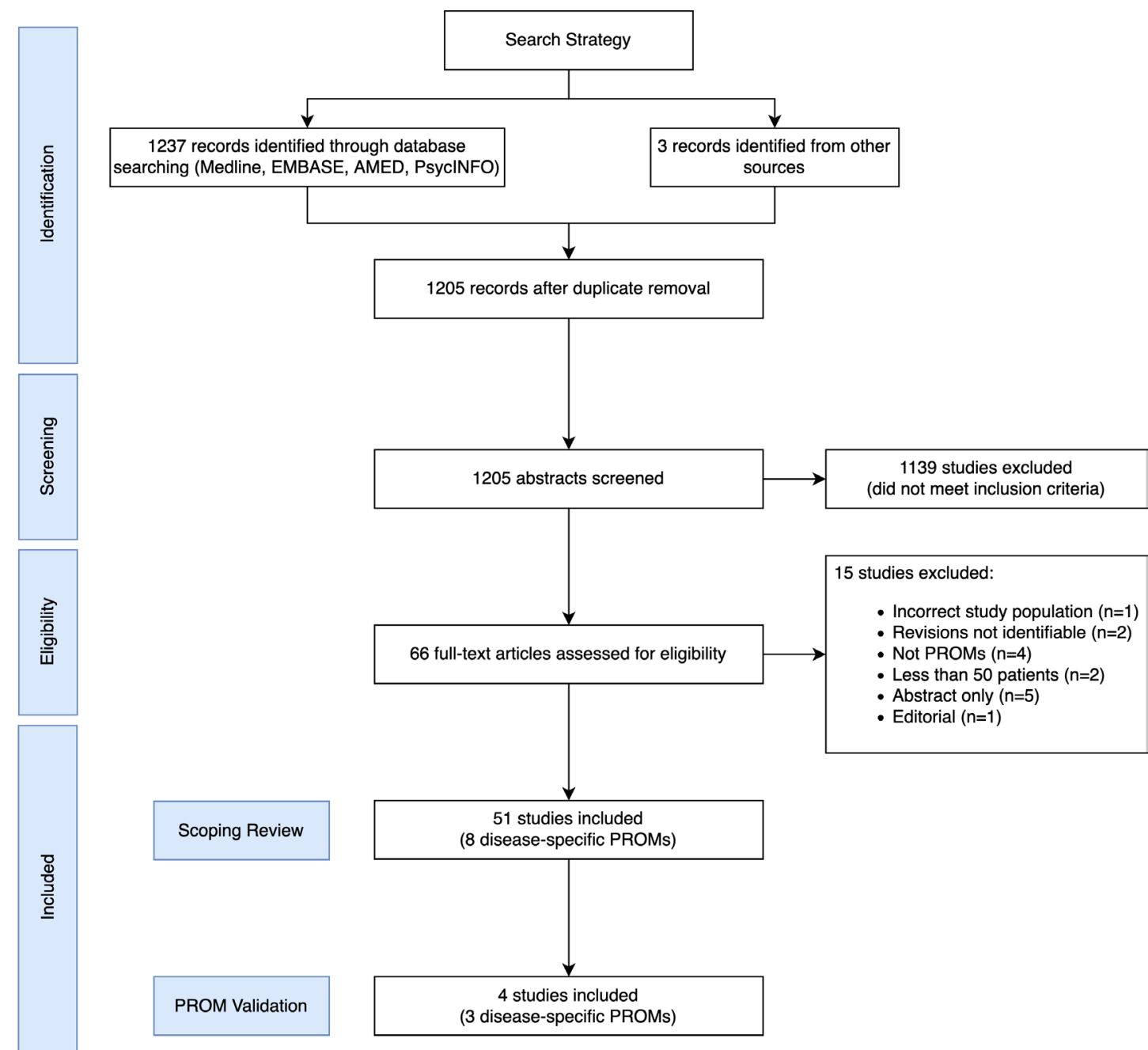

Figure 1 PRISMA flow diagram. The full search strategy is provided in online supplemental appendix 2. PROM, patientreported outcome measure.

prevent catastrophic joint failure or new comorbidity. To measure the success or otherwise of the outcome from discretionary revision knee replacement, one important aspect is the ability to measure pain and joint function from the perspective of the patient.

Patient-reported outcome measures (PROMs) are widely used for this purpose in lower limb surgery. Many PROMs aim to report quality of life and functional outcomes, while others assess sporting performance, activities of daily living or psychological health. However, not all have optimal measurement properties. ${ }^{78}$ For primary knee replacement, many PROMs have good quality evidence for their validity. ${ }^{9} 10$ This has facilitated utilisation of PROMs to support patient choice and manage healthcare providers, ${ }^{2} 1112$ with many schemes also including revision procedures. A prominent example is the NHS PROMs programme, ${ }^{2}$ which has collected data from more than 10000 patients who have undergone revision knee replacement. ${ }^{13}$ However, interpretation of this data has been critically limited by a lack of PROM validation.

Revision knee replacement is one of the most expensive procedures in modern healthcare ${ }^{14}$ and high-quality
PROM data is important to evaluate cost-effectiveness. ${ }^{15}$ While generic PROMs can be used to compare patients with different conditions, they may miss important items in specific populations. ${ }^{16}$ The COnsensus-based Standards for the selection of health status Measurement INstruments (COSMIN) initiative provides tools to aid systematic reviews and selection of measurement instruments. ${ }^{17}$ The ideal PROM is developed or subsequently validated in the population of interest, has good measurement properties (GMP) and is supported by high-quality evidence. PROM instruments meeting these criteria can be selected for a core outcome set in order to standardise outcome measurement. If there are no suitable PROMs, then further validation studies may be required or the development of a new PROM. For discretionary revision knee replacement, no systematic review has evaluated PROMs in current use, their measurement properties or the quality of this evidence. This limits meta-analysis of previous research and design of future trials.

The aims of this review were: (1) to scope the literature to identify PROMS in current use for evaluation of symptoms, health status or quality of life following discretionary revision (or re-revision) knee replacement, 
Table 1 Characteristics of studies reporting PROMs for revision knee replacement

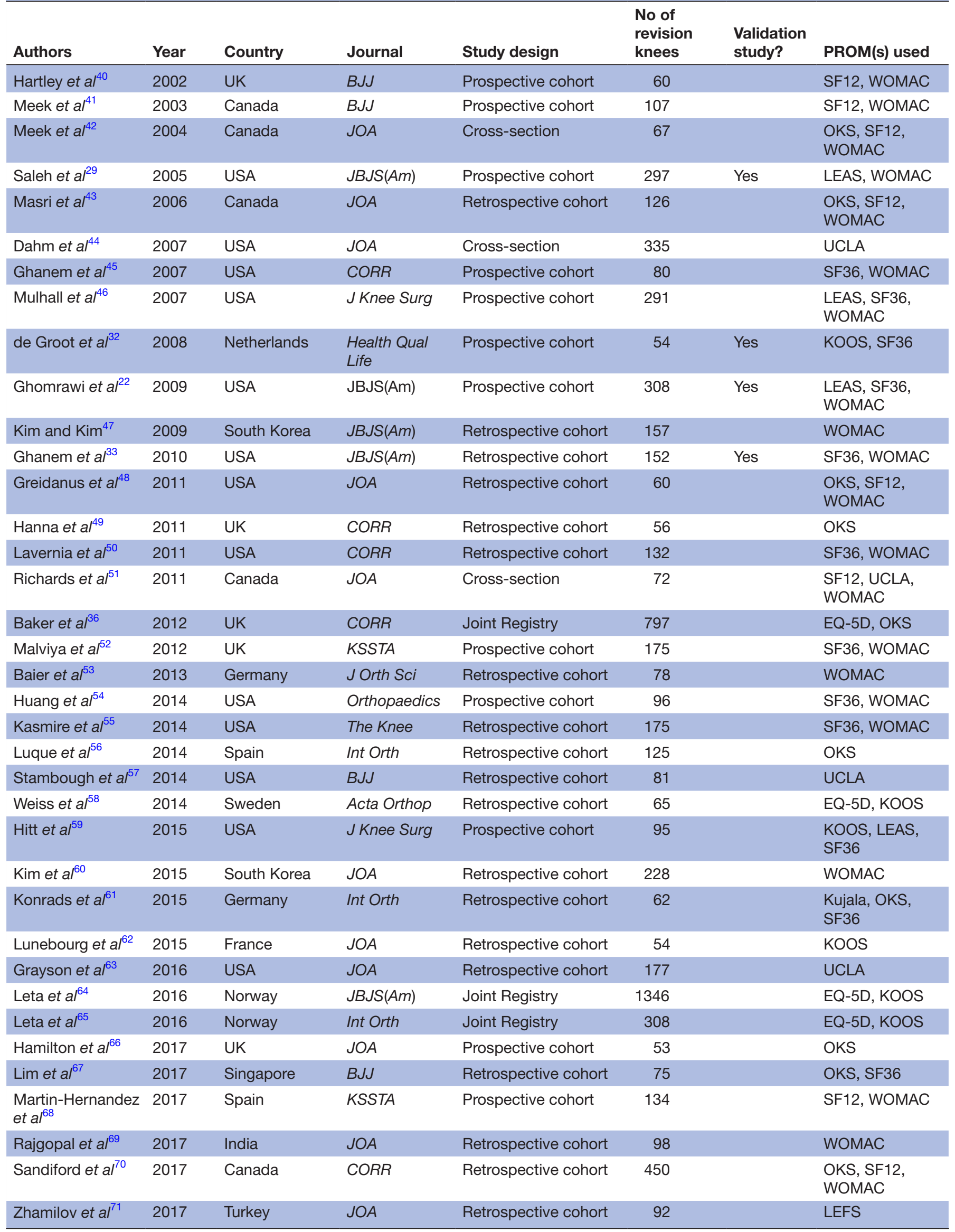


Table 1 Continued

\begin{tabular}{|c|c|c|c|c|c|c|c|}
\hline Authors & Year & Country & Journal & Study design & $\begin{array}{l}\text { No of } \\
\text { revision } \\
\text { knees }\end{array}$ & $\begin{array}{l}\text { Validation } \\
\text { study? }\end{array}$ & PROM(s) used \\
\hline Agarwal et al ${ }^{72}$ & 2018 & UK & The Knee & Prospective cohort & 104 & & EQ-5D, OKS \\
\hline Boelch et $a l^{73}$ & 2018 & Germany & Int Orth & $\mathrm{RCT}$ & 51 & & OKS, SF36 \\
\hline Eibich et $a l^{15}$ & 2018 & UK & BMJ Open & Routine data & 1391 & & EQ-5D, OKS \\
\hline $\begin{array}{l}\text { Gomez-Vallejo et } \\
\mathrm{al}^{74}\end{array}$ & 2018 & Spain & J Orth Traum & Retrospective cohort & 67 & & SF36, WOMAC \\
\hline Weber et $a l^{75}$ & 2018 & Germany & BioMed RI & Retrospective cohort & 68 & & EQ-5D, WOMAC \\
\hline $\begin{array}{l}\text { Bin Abd Razak } \\
\text { et } a^{76}\end{array}$ & 2019 & Singapore & J Knee Surg & Retrospective cohort & 163 & & OKS, SF36 \\
\hline Konrads et al $l^{77}$ & 2019 & Germany & J Knee Surg & Retrospective cohort & 135 & & $\begin{array}{l}\text { Kujala, OKS, } \\
\text { SF36 }\end{array}$ \\
\hline Stockwell et al ${ }^{81}$ & 2019 & Canada & The Knee & Retrospective cohort & 234 & & OKS \\
\hline Klim et $\left.a\right|^{82}$ & 2020 & Austria & KSSTA & Retrospective cohort & 93 & & SF36, WOMAC \\
\hline Larsen et $a l^{83}$ & 2020 & Denmark & $\begin{array}{l}\text { BMC Sports } \\
\text { Sci }\end{array}$ & Retrospective cohort & 51 & & KOOS \\
\hline Oliver et $a l^{84}$ & 2020 & Spain & Orth Surg & Retrospective cohort & 89 & & KOOS, Lysholm \\
\hline
\end{tabular}

KOOS, Knee Injury and Osteoarthritis Outcome Score; LEAS, Lower Extremity Activity Scale; LEFS, Lower Extremity Functional Scale; OKS, Oxford Knee Score; PROM, patient-reported outcome measure; SF, Short Form; UCLA, University of California at Los Angeles Activity Score; WOMAC, Western Ontario and McMaster Universities Arthritis Index.

and (2) to identify validated joint-specific PROMs, their measurement properties and quality of evidence.

\section{METHODS}

This section is structured to follow the COSMIN Handbook and a figure to illustrate our methods is provided in an online supplemental appendix $1 .^{17}$

\section{Patient and Public Involvement}

Patients and the public were involved in the design, or conduct, or reporting, or dissemination plans of our research. This article was motivated by the James Lind Alliance Priority Setting Partnership for revision knee replacement, ${ }^{18}$ particularly the question: 'How should we measure the outcomes following revision knee surgery in a way that is meaningful to patients?

\section{Part A: aim and literature search}

Step 1: Aims

Described above.

\section{Step 2: Study eligibility criteria}

Randomised and non-randomised studies were eligible for inclusion. Revision knee replacement was defined as any procedure where an arthroplasty component was removed, modified or added. This included isolated liner exchange, secondary patellar resurfacing and re-revision procedures. Studies where the majority of procedures were performed for non-discretionary indications (such as infection or malignancy) were excluded, as well as amputations and arthrodesis procedures. Since $85 \%$ of revisions are for discretionary indications, studies where the indication was not specified were deemed eligible for inclusion. PROMs were required to address one of the following domains:

- Pain (eg, Western Ontario and McMaster Universities Arthritis Index (WOMAC) pain subscale ${ }^{19}$ ),

- Function (eg, WOMAC functional limitation subscale),

- Combined pain and function (eg, Oxford Knee Score $^{20}$ ),

- Joint-related health status (eg, Knee Injury and Osteoarthritis Outcome Score (KOOS) quality of life $\left.(\mathrm{QOL})^{21}\right)$, or

- Patient activity (eg, Lower Extremity Activity Scale $\left(\right.$ LEAS $\left.^{22}\right)$.

Collectively, we have termed these 'joint-specific' PROMs. The focus of this study was not to examine generic health-related quality of life instruments (eg, EQ-5D $\mathrm{D}^{23}$ ). However, we did report the use of these instruments in conjunction with a joint-specific PROM. Outcome scores not considered to be patient-centred were excluded; for example, surgeon-completed scores such as the Bristol Knee Score (BKS) and the Knee Society Score (KSS). Studies with less than 50 patients were excluded as their sample size would be considered inadequate when 
Table 2 Summary characteristics for studies reporting PROMs following revision knee replacement

\begin{tabular}{ll}
\hline & Number of studies (\%) \\
\hline No of patients & Median 104 (range 51-1391) \\
Continent & \\
\hline Europe & $25(49)$ \\
\hline North America & $19(37.3)$ \\
\hline Asia & $6(11.8)$ \\
\hline Australasia & $1(2)$ \\
\hline Type of study & \\
\hline Randomised controlled trial & $1(2)$ \\
\hline Prospective cohort & $14(27.5)$ \\
\hline Retrospective cohort & $29(56.9)$ \\
\hline Joint Registry & $3(5.9)$ \\
\hline Routine data analysis & $1(2)$ \\
\hline Cross-sectional survey & $3(5.9)$ \\
\hline Joint-specific PROMs & \\
\hline KOOS & $8(15.7)$ \\
\hline Kujala & $2(3.9)$ \\
\hline LEAS & $4(7.8)$ \\
\hline LEFS & $1(2)$ \\
\hline Lysholm & $1(2)$ \\
\hline OKS & $19(37.3)$ \\
\hline UCLA & $4(7.8)$ \\
\hline WOMAC & $25(49)$ \\
\hline Generic PROMs & \\
\hline EQ-5D & $7(13.7)$ \\
\hline SF12 & $8(15.7)$ \\
\hline SF36 & $18(35.3)$ \\
\hline
\end{tabular}

Number of studies reporting each measure (\%)

KOOS, Knee Injury and Osteoarthritis Outcome Score; LEAS, Lower Extremity Activity Scale; LEFS, Lower Extremity Functional Scale; OKS, Oxford Knee Score; PROM, patient-reported outcome measure; SF, Short Form; UCLA, University of California at Los Angeles Activity Score; WOMAC, Western Ontario and McMaster Universities Arthritis Index.

applying COSMIN rules for rating of measurement properties and evidence quality. ${ }^{10}$

\section{Step 3: search strategy}

This is provided in online supplemental appendix 2. MEDLINE, Embase, AMED and PsycINFO were searched on 1 July 2020 using the Oxford PROM filter. ${ }^{24}$ Searches were translated for each database. There were no limitations on language or publication date. The citations of included studies were searched to identify additional articles.

\section{Step 4: study selection}

Two authors (SAS and EAH) independently reviewed title and abstract for all records returned by the search against eligibility criteria. Disagreement was resolved through discussion of the full text publication. Data were extracted using a calibrated form on name and type of PROM, geography, journal, year of publication and number of patients. Data were summarised using counts with percentage frequency for each of the data items collected.

\section{Part B: evaluation of measurement properties of the included PROMs}

Steps 5, 6 and 7: content validity, internal structure, reliability and responsiveness

Descriptions of terminology for measurement properties are provided in online supplemental appendix 3. Each measurement property was evaluated in three separate sub-steps:

\section{Substep 1: evaluation of methodological quality}

Two authors (SAS and SGFA) independently evaluated the measurement properties in each article against the COSMIN Risk of Bias checklist. A priori hypotheses for construct validity and responsiveness were set (online supplemental appendix 4, table 1). Study quality was assessed separately for each measurement property using a four-point rating system (very good, adequate, doubtful or inadequate). The 'worst score counts' principle was used, where the overall rating for each measurement property is given by the lowest rating of any standard in the box. ${ }^{25}$

\section{Substep 2: application of criteria for GMP}

Two authors (SAS and SGFA) independently extracted data on: PROM characteristics (intended construct for measurement, measurement properties, method of administration), study sample (number of patients, patient demographics, diagnosis) and study details (setting, country, language). The few disagreements were resolved through discussion. The results from each study on a measurement property were assigned a quality rating as: sufficient $(+)$, insufficient $(-)$ or indeterminate (?).

\section{Substep 3: summary and grading of quality of evidence}

This section refers to rating the quality of the PROM as a whole. PROMs were qualitatively summarised and assigned a four-point quality rating. A modified Grading of Recommendations Assessment, Development and Evaluation (GRADE) approach (omitting publication bias) was used to assign evidence quality as high, moderate, low or very low. ${ }^{26}$

\section{Part C: selecting a PROM}

Step 8: description of interpretability and feasibility

Interpretability and feasibility were analysed descriptively as per COSMIN guidance. ${ }^{17}$

\section{Step 9: formulation of recommendations}

PROMs were categorised into three categories: (A) Sufficient content validity and at least low-quality evidence for internal consistency; (B) Between 'A' and 'C'; and (C) 


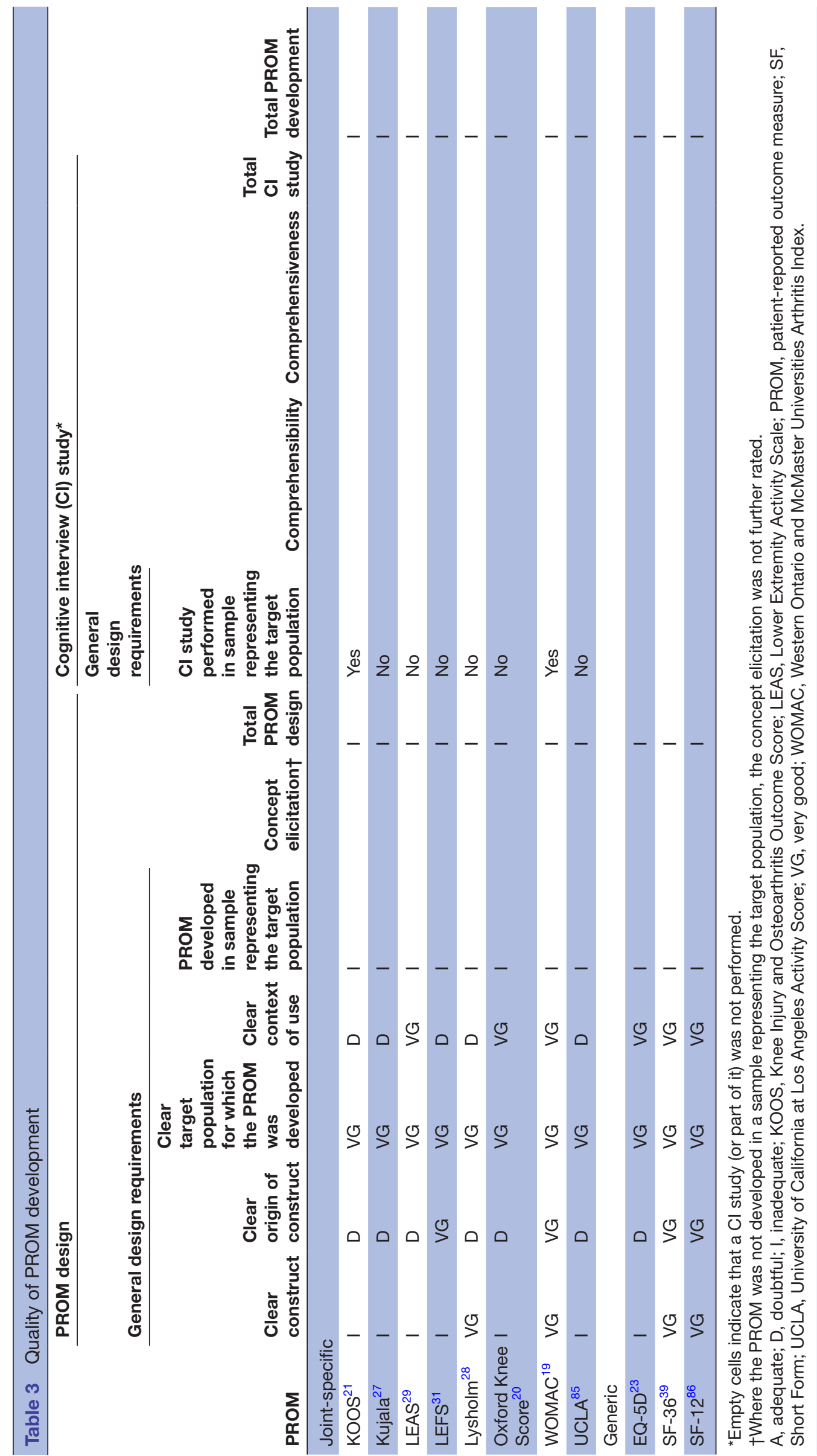




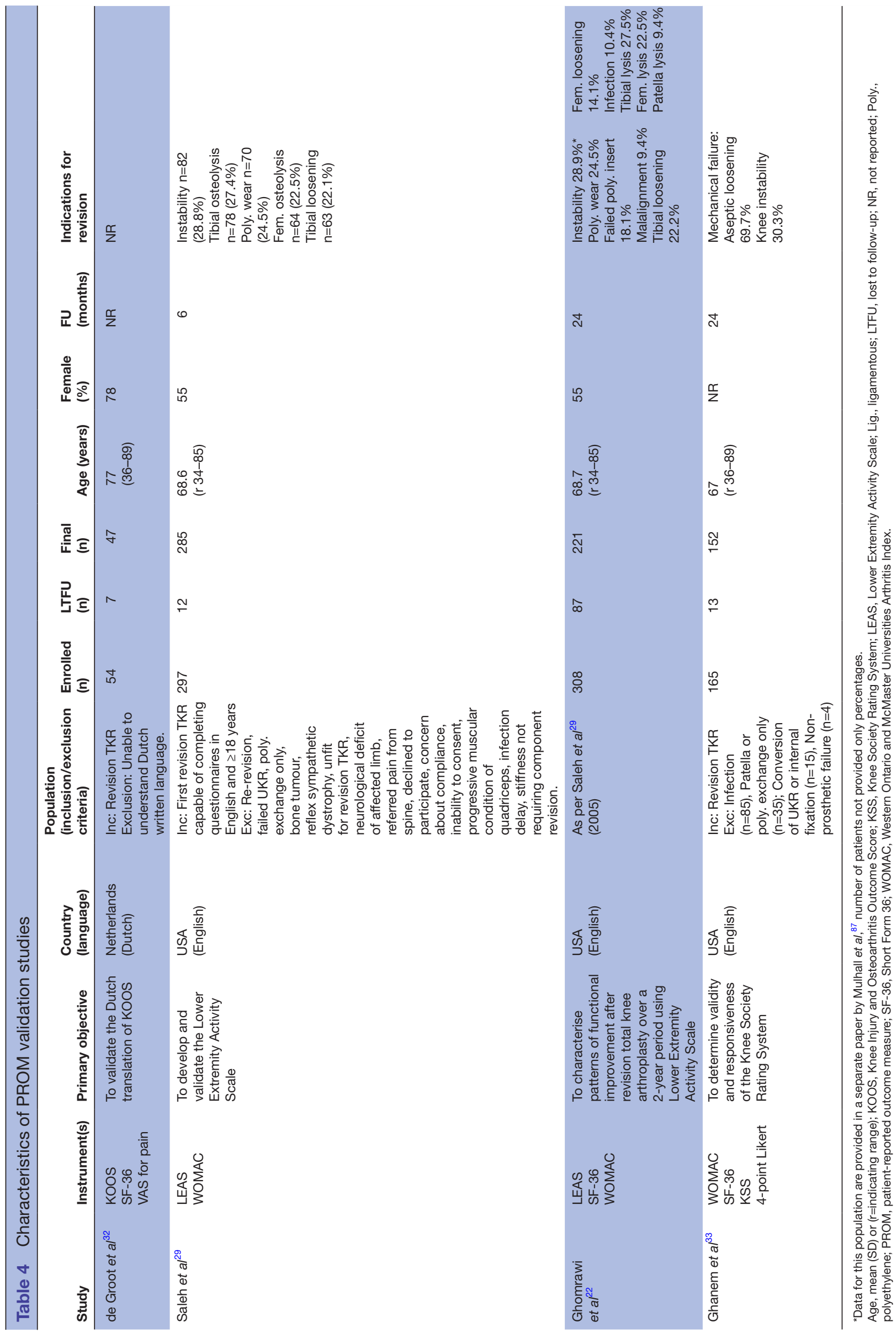


Table 5 Characteristics of the joint-specific PROMs evaluated in validation studies

\begin{tabular}{llllll}
\hline & $\begin{array}{l}\text { Year } \\
\text { developed }\end{array}$ & $\begin{array}{l}\text { Original } \\
\text { language }\end{array}$ & Target population & $\begin{array}{l}\text { Intended construct/ } \\
\text { domains }\end{array}$ & $\begin{array}{l}\text { Best/ } \\
\text { worst } \\
\text { questions }\end{array}$ \\
\hline score
\end{tabular}

following knee injury function

Sports and recreation

function

Knee-related quality of life

\begin{tabular}{|c|c|c|c|c|c|c|}
\hline WOMAC $^{19}$ & 1982 & English & $\begin{array}{l}\text { Patients with OA of the } \\
\text { hip or knee }\end{array}$ & $\begin{array}{l}\text { Pain } \\
\text { Stiffness } \\
\text { Function and daily activities }\end{array}$ & $\begin{array}{l}24 \\
\text { questions }\end{array}$ & $0 / 96$ \\
\hline \multicolumn{7}{|l|}{ Activity level } \\
\hline LEAS $^{29}$ & 2005 & English & $\begin{array}{l}\text { Patients awaiting or had } \\
\text { undergone primary or } \\
\text { revision lower limb joint } \\
\text { replacement }\end{array}$ & Physical activity & 1 question & $18 / 1$ \\
\hline
\end{tabular}

KOOS, Knee Injury and Osteoarthritis Outcome Score; LEAS, Lower Extremity Activity Scale; PROM, patient-reported outcome measure; SF36, Short Form 36; WOMAC, Western Ontario and McMaster Universities Arthritis Index.

High-quality evidence for an insufficient measurement property. PROMs rated 'A' can be recommended for use. PROMs rated ' $\mathrm{B}$ ' have potential for recommendation but require further evaluation. PROMs rated ' $\mathrm{C}$ ' should not be recommended.

Step 10: reporting of the systematic review

The Preferred Reporting Items for Systematic Reviews and Meta-Analyses (PRISMA) flow diagram is provided in figure 1.

\section{RESULTS}

\section{Part A}

\section{Study selection}

One thousand two hundred and five unique articles were identified for screening. Sixty-six full text articles were assessed for eligibility. Fifty-one studies were included in the scoping review, reporting on eight joint-specific PROMs. Four studies met inclusion criteria for PROM validation, describing measurement properties for three PROMs (figure 1).

\section{Characteristics of studies reporting PROM outcomes for revision} knee replacement

Fifty-one studies reported on PROM outcomes (tables 1 and 2) recruiting a median of 104 (range 51-1391) patients. Study designs included $1(2.0 \%)$ randomised controlled trial, $14(27.5 \%)$ prospective cohort studies, $29(56.9 \%)$ retrospective cohort studies, $3(5.9 \%)$ reports from national joint registries, $3(5.9 \%)$ cross-sectional surveys and $1(2.0 \%)$ data analysis of routinely collected secondary care data. Twenty-five studies $(49.0 \%)$ were from Europe, 19 (37.3\%) from North America, 6
(11.8\%) from Asia and $1(2.0 \%)$ from Australasia. The joint-specific PROMs reported were the WOMAC Index (25 studies, 49.0\%), Oxford Knee Score (OKS) (19 studies, $37.3 \%$ ), KOOS (8 studies, $15.7 \%$ ), LEAS (4 studies, 7.8\%), University of California at Los Angeles Activity Score (UCLA, 4 studies, $7.8 \%$ ), Kujala score (2 studies, 3.9\%), Lower Extremity Functional Scale (LEFS, 2 studies, 3.9\%) and the Lysholm score (1 study, 2.0\%). The majority of studies were published within the past 5 years $(27 / 51(52.9 \%)$ studies) (online supplemental appendix 4 , figure 1 ).

\section{Part B}

Quality of PROM development studies

The quality of PROM development for the eight diseasespecific PROMs identified in Part A is summarised in table 3 . The construct to be measured was clear in two studies $(25 \%)$, with the remainder rated 'inadequate'. One example of a study rated 'inadequate' was the Kujala study. ${ }^{27}$ This rating was made because, while the score was designed to measure anterior knee symptoms, the specific aspects of these symptoms to be measured were not described (such as pain intensity or pain interference). The Lysholm score ${ }^{28}$ was rated 'very good' due to a specific description (defining 'the lowest activity level needed during walking, running or jumping to produce giving way or pain and swelling'). The origin of the construct to be measured was clear in only two studies (25.0\%). One example of a study rated 'very good' for this property was the LEFS study, ${ }^{29}$ which referenced the WHO's International Classification of Functioning, Disability and Health (ICF) conceptual framework. ${ }^{30}$ The context of use was rated 'very good' for three studies 


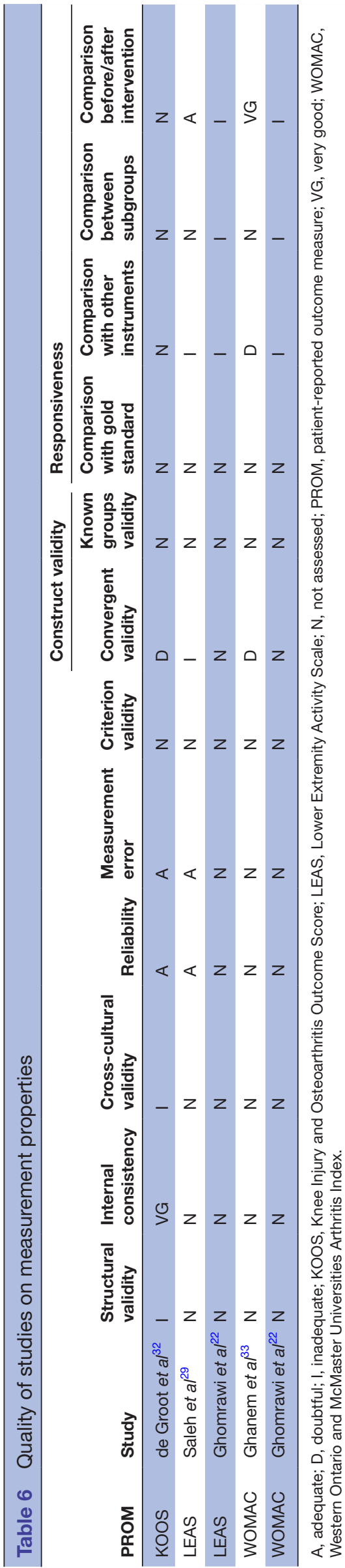

$(37.5 \%)$. These studies provided at least one clear description of the intended application of the instrument. For example, the OKS was designed to evaluate patients before and after knee replacement surgery. ${ }^{20}$ All studies were rated as 'very good' for their description of a clear target population. While many studies provided a very broad description (eg, the LEFS described patients 'with lower extremity orthopaedic conditions ${ }^{31}$ ), the COSMIN guidance is permissive for rating this property. However, the PROM development sample was rated 'inadequate' for all studies either because the patient sample was not correspondingly broad or, taking a view on the patient sample of interest in this review, did not recruit a sample representative of discretionary revision knee replacement. While the LEAS study did recruit patients with revision knee replacements for some aspects of PROM development, a surgeon panel was used in lieu of patients for content validity, justifying an 'inadequate' rating. ${ }^{29} \mathrm{In}$ summary, the total PROM development was rated 'inadequate' for all studies based on the 'worst score counts' principle recommended by COSMIN. However, this does not reflect positive ratings for some aspects of PROM development as described above.

Characteristics of PROM validation studies

Four studies 22293239 from the scoping review validated three joint-specific PROMs (KOOS, LEAS, WOMAC) (table 4). The mean age of patients in the included studies ranged from 67 to 77 years. Female patients accounted for $50 \%$ to $78 \%$ of the study populations. The primary objective of the included articles varied from validation of a PROM, validation of another instrument with the PROM as a comparator, development of a new instrument and reporting of clinical outcome after revision knee replacement. The characteristics of the PROMs included in the validation studies are described in table 5 .

\section{Quality of studies on measurement properties}

In total, 20 measurement properties for the KOOS, LEAS and WOMAC were evaluated (table 6). There were 40 additional opportunities to evaluate measurement properties that were not attempted. Two $(10.0 \%)$ measurement properties were rated 'very good', 5 (25.0\%) 'adequate', $3(15.0 \%)$ 'doubtful' and $10(50.0 \%)$ 'inadequate'. For structural validity, de Groot's evaluation for the KOOS was rated 'inadequate' due to an insufficient sample size for factor analysis (less than five times the number of participants). Three out of four (75.0\%) studies that reported on responsiveness were rated 'inadequate' due to their construct approach. For example, Saleh $e t a l^{29}$ used an 'inadequate' comparator instrument for development of the LEAS - the measurement properties of the WOMAC are not well enough known for revision. Ghomrawi $e t a l^{22}$ did not set hypotheses for construct validity, and their statistical methodology did not allow these to be evaluated at review. Two studies reported on reliability. These were rated 'adequate' as, while they chose an appropriate interval, they did not also ensure patients were stable. 
Table 7 Quality of the evidence for measurement properties of the PROMs

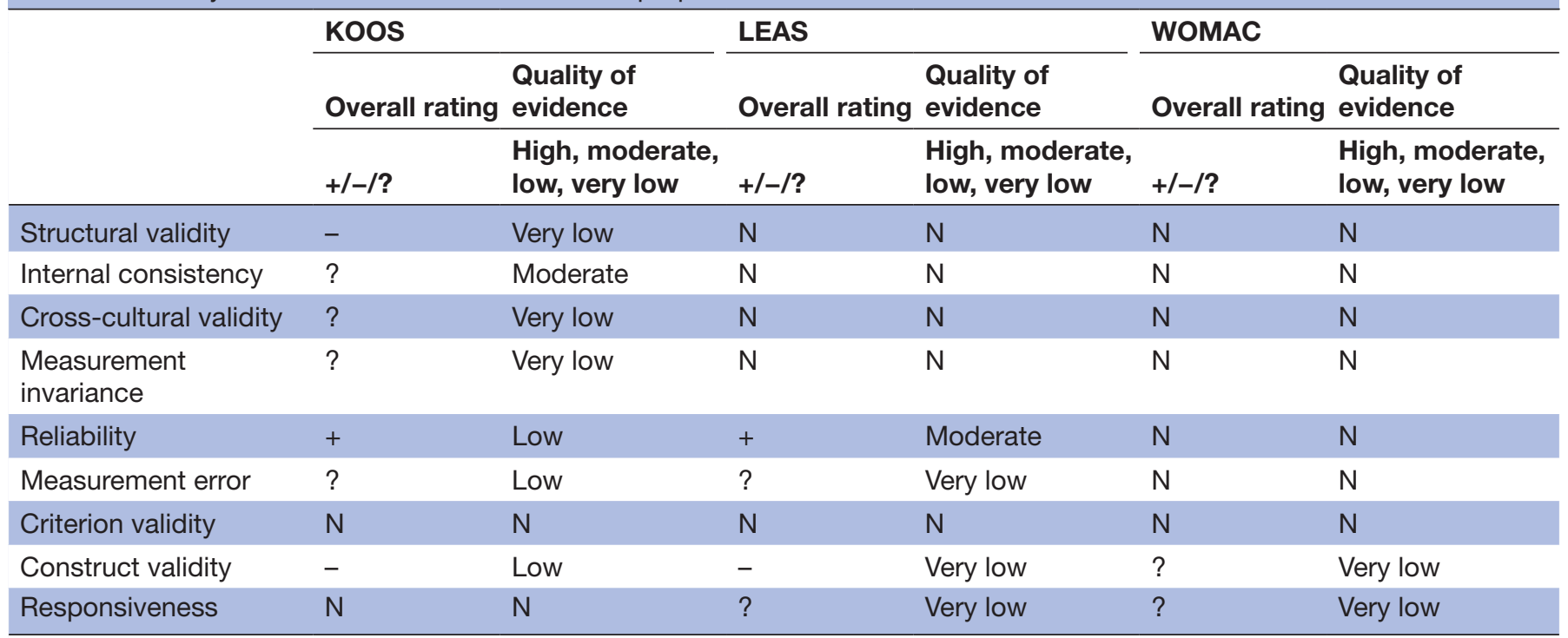

$+=$ sufficient, $-=$ insufficient, $?=$ indeterminate.

KOOS, Knee Injury and Osteoarthritis Outcome Score; LEAS, Lower Extremity Activity Scale; N, not assessed; PROM, patient-reported outcome measure; WOMAC, Western Ontario and McMaster Universities Arthritis Index.

Quality of the evidence for measurement properties of the PROMs The quality of the evidence for measurement properties of the included PROMs is provided in table 7. Twenty-five out of $27(92.6 \%)$ measurement properties were rated insufficient, indeterminate or not assessed. The only measurement property to receive a 'sufficient' rating was reliability for both the KOOS and the LEAS, supported by 'low' and 'moderate' quality evidence, respectively.

\section{Part C}

Data on the interpretability of the studies is summarised in table 8 . The mode of PROM administration was unclear for all studies except de Groot et al. ${ }^{32}$ Missing responses ranged from $25 \%$ to $60 \%$. No study reported on missing items within a PROM instrument. Floor and ceiling effects were not reported, except by Saleh et al. ${ }^{29}$ No PROM met criteria either to be recommended or not recommended for use. Each of the validated PROMs (ie, KOOS, LEAS and WOMAC) was therefore assigned recommendation ' $\mathrm{B}$ ', indicating that further evidence is needed.

\section{DISCUSSION}

This review has demonstrated the increasing use of PROMs to evaluate symptoms and functional outcomes following discretionary revision knee replacement. The majority of studies were retrospective and observational, with only one randomised controlled trial. Eight different joint-specific PROMs were identified, with the WOMAC index (25 studies, 49.0\%) and the OKS (19 studies, $37.3 \%$ ) the most frequent. Only three joint-specific PROMs were supported by a validation study: KOOS, LEAS and WOMAC. Each of these validation studies had 'low' or 'very low' quality evidence and the majority of measurement properties were either not evaluated or rated 'inadequate' or 'indeterminate'. As such, each of these PROMs requires more evidence in order to be recommended for use.

\section{Secondary findings and relation to other studies}

Musculoskeletal disorders account for one-third of all reviews on the COSMIN database. ${ }^{34}$ At least three reviews have evaluated the measurement properties of PROMs following primary knee replacement. ${ }^{9} 1035$ These studies found that many PROM instruments had limited evidence to support their measurement properties, justifying the need for further research. We are not aware of previous reviews that have examined the measurement properties of PROMs following discretionary revision knee replacement. While many of the goals from discretionary revision knee replacement are shared with primary knee replacement, there are important differences in the patient populations and disease processes being treated and the surgical interventions themselves. For example, while primary knee replacement treats predominantly osteoarthritis, discretionary revision knee replacement treats many varied disease processes. ${ }^{36}$ The revision patient population is also more comorbid and may have different expectations from surgery. ${ }^{37}$ As such, the evidence for PROMs developed in primary knee replacement cannot necessarily be assumed to be transferable across.

\section{Strengths and weaknesses}

This study has a number of important strengths, including the use of a broad search strategy based on the Oxford PROM filter ${ }^{24}$ and the application of latest COSMIN guidelines. The use of a priori hypotheses by our review team to evaluate construct validity and responsiveness is novel and meant these properties could be considered even when not a focus of the original article. This study 


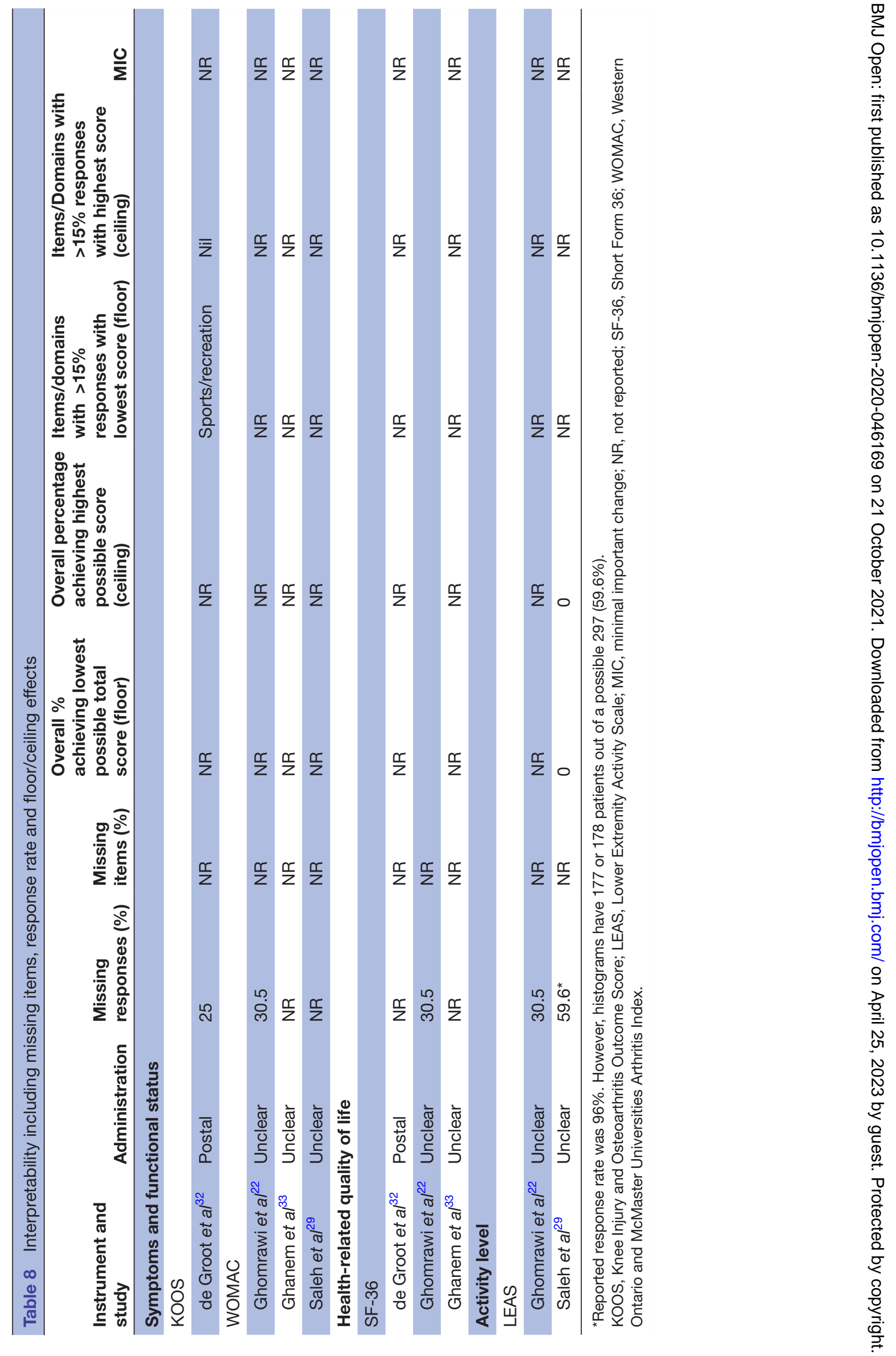


was motivated by the James Lind Alliance Priority Setting Partnership for revision knee replacement, which generated the question: 'How should we measure the outcomes following revision knee surgery in a way that is meaningful to patients?'. ${ }^{38}$ As such, outcome scores that were not patient completed were excluded. We acknowledge that this has restricted the number of eligible studies from North America, where use of the KSS is prevalent. In the future, qualitative studies to explore patients' reasons for choosing surgery and to identify the outcomes that are most important to patients may be needed.

\section{Implications for practice}

We have not put forward a PROM for recommendation because the quality of the available evidence was low, and data were lacking for many of the measurement properties. However, we can make recommendations to direct future research and to move towards developing a core outcome set for discretionary revision knee replacement. First, we wish to highlight that standards for reporting of psychometric studies have changed considerably over the past 20 years. ${ }^{9}$ COSMIN tools are not limited to systematic reviews and may be used guide the scope and detail required to develop a new instrument or to evaluate an existing one. Second, this study has highlighted a number of common methodological flaws that result in high risk of bias. For example, when evaluating structural validity, none of the validation studies performed confirmatory factor analysis to understand whether the PROM scores reflected the dimensionality of the construct. For reliability, test conditions were not recorded with sufficient detail to ensure that not only the repeat interval was appropriate but also that the patient remained stable. For interpretability, none of the studies calculated a minimal important change nor comprehensively assessed floor and ceiling effects. Third, we recommend that future studies planning to use an existing joint-specific PROM to evaluate outcomes after revision surgery do so in conjunction with a validated generic health-related quality of life instrument (such as the Short Form-36 (SF36) ${ }^{39}$ or EQ-5D $\mathrm{D}^{23}$ ). While neither the EQ-5D or SF36 were developed in patients undergoing revision knee replacement, their measurement properties have been studied extensively and allow generalisability between different conditions. This approach will provide valuable information on construct validity and responsiveness in the future.

\section{CONCLUSION}

In conclusion, joint-specific PROMs are increasingly used to report outcomes following revision knee replacement, but these instruments have insufficient evidence for validity. Future research is needed to target the deficiencies highlighted by this review in order to inform clinical trials and observational studies evaluating these outcomes.
Contributors SAS: concept, study selection and scoping review, assessment of methodological quality, analysis, writing and editing paper, guarantor. EAH: study selection and scoping review, critically revising paper. SGFA: assessment of methodological quality, critically revising paper. AA: critically revising paper. AJP: concept, methodology, writing and editing paper. $\mathrm{SH}$ : concept, methodology, writing and editing paper.

Funding SAS has received funding from the Royal College of Surgeons One-Year Fellowship, Rosetrees Trust and National Institute for Health Research (NIHR).

Competing interests None declared.

Patient consent for publication Not applicable.

Provenance and peer review Not commissioned; externally peer reviewed.

Data availability statement All data relevant to the study are included in the article or uploaded as supplementary information.

Supplemental material This content has been supplied by the author(s). It has not been vetted by BMJ Publishing Group Limited (BMJ) and may not have been peer-reviewed. Any opinions or recommendations discussed are solely those of the author(s) and are not endorsed by BMJ. BMJ disclaims all liability and responsibility arising from any reliance placed on the content. Where the content includes any translated material, BMJ does not warrant the accuracy and reliability of the translations (including but not limited to local regulations, clinical guidelines, terminology, drug names and drug dosages), and is not responsible for any error and/or omissions arising from translation and adaptation or otherwise.

Open access This is an open access article distributed in accordance with the Creative Commons Attribution Non Commercial (CC BY-NC 4.0) license, which permits others to distribute, remix, adapt, build upon this work non-commercially, and license their derivative works on different terms, provided the original work is properly cited, appropriate credit is given, any changes made indicated, and the use is non-commercial. See: http://creativecommons.org/licenses/by-nc/4.0/.

ORCID iDs

Shiraz A Sabah http://orcid.org/0000-0003-2401-1372

Simon G F Abram http://orcid.org/0000-0002-4452-6499

\section{REFERENCES}

1 Price AJ, Alvand A, Troelsen A, et al. Knee replacement. Lancet 2018;392:1672-82.

2 NHS Digital. Patient Reported Outcome Measures (PROMs) [Internet]. Available: https://digital.nhs.uk/data-and-information/ data-tools-and-services/data-services/patient-reported-outcomemeasures-proms [Accessed 23 Jun 2021].

3 Scott CEH, Oliver WM, MacDonald D, et al. Predicting dissatisfaction following total knee arthroplasty in patients under 55 years of age. Bone Joint J 2016;98-B:1625-34.

4 Niinimäki TT, Murray DW, Partanen J, et al. Unicompartmental knee arthroplasties implanted for osteoarthritis with partial loss of joint space have high re-operation rates. Knee 2011;18:432-5.

5 Wylde V, Howells N, Bertram W, et al. Development of a complex intervention for people with chronic pain after knee replacement: the StAR care pathway. Trials 2018;19:61.

6 National Joint Registry for England Wales Northern Ireland and the Isle of Man. NJR 17th annual report, 2020.

7 Garratt A, Schmidt L, Mackintosh A, et al. Quality of life measurement: bibliographic study of patient assessed health outcome measures. BMJ 2002;324:1417-9.

8 Abram SGF, Middleton R, Beard DJ, et al. Patient-Reported outcome measures for patients with meniscal tears: a systematic review of measurement properties and evaluation with the COSMIN checklist. BMJ Open 2017;7:1-15.

9 Harris K, Dawson J, Gibbons E, et al. Systematic review of measurement properties of patient-reported outcome measures used in patients undergoing hip and knee arthroplasty. Patient Relat Outcome Meas 2016;7:101-8.

10 Gagnier JJ, Mullins M, Huang $\mathrm{H}$, et al. A systematic review of measurement properties of patient-reported outcome measures used in patients undergoing total knee arthroplasty. J Arthroplasty 2017;32:1688-97.

11 National Joint Registry for England, Wales NI and the I of M. NJR Clinician Feedback - Surgeon PROMs Reports [Internet]. Available: https://clinicianfeedback.njrcentre.org.uk/SurgeonPromsReports. aspx [Accessed 28 Apr 2020].

12 Middleton R, Wilson HA, Alvand A, et al. Outcome-based commissioning of knee arthroplasty in the NHS: system error in a 
national monitoring programme and the unintended consequences on achieving the best practice tariff. Bone Joint J 2018;100B:1572-8.

13 Sabah SA, Alvand A, Knight R, et al. Patient-Reported function and quality of life after revision total knee arthroplasty: an analysis of 10,727 patients from the NHS PROMs program. $J$ Arthroplasty 2021;36:2887-95.

14 Kallala RF, Vanhegan IS, Ibrahim MS, et al. Financial analysis of revision knee surgery based on NHS tariffs and hospital costs. Bone Joint J 2015;97-B:197-201.

15 Eibich P, Dakin HA, Price AJ, et al. Associations between preoperative Oxford hip and knee scores and costs and quality of life of patients undergoing primary total joint replacement in the NHS England: an observational study. BMJ Open 2018;8:e019477.

16 Brazier JE, Harper R, Munro J, et al. Generic and condition-specific outcome measures for people with osteoarthritis of the knee. Rheumatology 1999;38:870-7.

17 Prinsen CAC, Mokkink LB, Bouter LM, et al. COSMIN guideline for systematic reviews of patient-reported outcome measures. Qual Life Res 2018;27:1147-57.

18 Mathews JA, Kalson NS, Tarrant PM, et al. Top ten research priorities for problematic knee arthroplasty. Bone Joint J 2020;102B:1176-82.

19 Bellamy N, Buchanan WW, Goldsmith $\mathrm{CH}$, et al. Validation study of WOMAC: a health status instrument for measuring clinically important patient relevant outcomes to antirheumatic drug therapy in patients with osteoarthritis of the hip or knee. J Rheumatol 1988;15:1833-40.

20 Dawson J, Fitzpatrick R, Murray D, et al. Questionnaire on the perceptions of patients about total knee replacement. J Bone Joint Surg Br 1998;80:63-9.

21 Roos EM, Roos HP, Lohmander LS, et al. Knee Injury and Osteoarthritis Outcome Score (KOOS)--development of a selfadministered outcome measure. J Orthop Sports Phys Ther 1998;28:88-96.

22 Ghomrawi HMK, Kane RL, Eberly LE, et al. Patterns of functional improvement after revision knee arthroplasty. J Bone Joint Surg Am 2009;91:2838-45.

23 EuroQol Group. EuroQol--a new facility for the measurement of health-related quality of life. Health Policy 1990;16:199-208.

24 Oxford PROM Group. Oxford PROM filter, 2010.

25 Terwee CB, Mokkink LB, Knol DL, et al. Rating the methodological quality in systematic reviews of studies on measurement properties: a scoring system for the COSMIN checklist. Qual Life Res 2012;21:651-7.

26 GRADE Working Group. Handbook for grading the quality of evidence and the strength of recommendations using the GRADE approach. [Internet], 2013. Available: https://gdt.gradepro.org/app/ handbook/handbook.html [Accessed 22 Mar 2020].

27 Kujala UM, Jaakkola LH, Koskinen SK, et al. Scoring of patellofemoral disorders. Arthroscopy 1993;9:159-63.

28 Lysholm J, Gillquist J. Evaluation of knee ligament surgery results with special emphasis on use of a scoring scale. Am J Sports Med 1982;10:150-4.

29 Saleh KJ, Mulhall KJ, Bershadsky B, et al. Development and validation of a lower-extremity activity scale. use for patients treated with revision total knee arthroplasty. J Bone Joint Surg Am 2005;87:1985-94.

30 World Health Organisation. International Classification of Functioning, Disability and Health (ICF) [Internet]. Available: https://www.who.int/ classifications/international-classification-of-functioning-disabilityand-health [Accessed 23 Jun 2021].

31 Binkley J, Stratford P, Lott S. DR-P, 1999 undefined. The Lower Extremity Functional Scale (LEFS): scale development, measurement properties, and clinical application. academic.oup.com [Internet]. Available: https://academic.oup.com/ptj/article-abstract/79/4/371/ 2857730 [Accessed 03 Jul 2020].

32 de Groot IB, Favejee MM, Reijman M, et al. The Dutch version of the knee injury and osteoarthritis outcome score: a validation study. Health Qual Life Outcomes 2008;6:16.

33 Ghanem E, Pawasarat I, Lindsay A, et al. Limitations of the knee Society score in evaluating outcomes following revision total knee arthroplasty. J Bone Joint Surg Am 2010;92:2445-51.

34 COSMIN. COSMIN Database of Systematic Reviews [Internet]. Available: https://www.cosmin.nl/tools/database-systematic-reviews/ [Accessed 01 Jul 2020].

35 Alviar MJ, Olver J, Brand C, et al. Do patient-reported outcome measures in hip and knee arthroplasty rehabilitation have robust measurement attributes? A systematic review. J Rehabil Med 2011;43:572-83.
36 Baker P, Cowling P, Kurtz S, et al. Reason for revision influences early patient outcomes after aseptic knee revision. Clin Orthop Relat Res 2012;470:2244-52.

37 Singh JA, Lewallen DG. Depression in primary TKA and higher medical comorbidities in revision TKA are associated with suboptimal subjective improvement in knee function. BMC Musculoskelet Disord 2014;15:127.

38 James Lind Alliance. Revision knee replacement top 10 priorities. Available: https://www.jla.nihr.ac.uk/priority-setting-partnerships/ Revision-knee-replacement/revision-knee-replacementtop-10priorities.htm [Accessed 20 Aug 2020]

39 Ware JE, Sherbourne CD. The mos 36-item short-form health survey (SF-36). I. conceptual framework and item selection. Med Care 1992;30:473-83.

40 Hartley RC, Barton-Hanson NG, Finley R, et al. Early patient outcomes after primary and revision total knee arthroplasty. A prospective study. J Bone Joint Surg Br 2002;84:994-9.

41 Meek RMD, Greidanus NV, McGraw RW, et al. The extensile rectus snip exposure in revision of total knee arthroplasty. J Bone Joint Surg $\mathrm{Br}$ 2003;85:1120-2.

42 Meek RMD, Dunlop D, Garbuz DS, et al. Patient satisfaction and functional status after aseptic versus septic revision total knee arthroplasty using the PROSTALAC articulating spacer. J Arthroplasty 2004;19:874-9.

43 Masri BA, Meek RMD, Greidanus NV, et al. Effect of retaining a patellar prosthesis on pain, functional, and satisfaction outcomes after revision total knee arthroplasty. J Arthroplasty 2006;21:1169-74

44 Dahm DL, Barnes SA, Harrington JR, et al. Patient reported activity after revision total knee arthroplasty. J Arthroplasty 2007;22:106-10.

45 Ghanem E, Restrepo C, Joshi A, et al. Periprosthetic infection does not preclude good outcome for revision arthroplasty. Clin Orthop Relat Res 2007;461:54-9.

46 Mulhall KJ, Ghomrawi HM, Mihalko W, et al. Adverse effects of increased body mass index and weight on survivorship of total knee arthroplasty and subsequent outcomes of revision TKA. J Knee Surg 2007;20:199-204.

$47 \mathrm{Kim} \mathrm{Y-H,} \mathrm{Kim} \mathrm{J-S.} \mathrm{Revision} \mathrm{total} \mathrm{knee} \mathrm{arthroplasty} \mathrm{with} \mathrm{use} \mathrm{of}$ a constrained condylar knee prosthesis. J Bone Joint Surg Am 2009:91:1440-7.

48 Greidanus NV, Peterson RC, Masri BA, et al. Quality of life outcomes in revision versus primary total knee arthroplasty. J Arthroplasty 2011;26:615-20.

49 Hanna SA, Aston WJS, de Roeck NJ, et al. Cementless revision TKA with bone grafting of osseous defects restores bone stock with a low revision rate at 4 to 10 years. Clin Orthop Relat Res 2011;469:3164-71.

50 Lavernia C, Contreras JS, Alcerro JC. The peel in total knee revision: exposure in the difficult knee. Clin Orthop Relat Res 2011;469:146-53.

51 Richards CJ, Garbuz DS, Pugh L, et al. Revision total knee arthroplasty: clinical outcome comparison with and without the use of femoral head structural allograft. J Arthroplasty 2011;26:1299-304

52 Malviya A, Brewster NT, Bettinson K, et al. Functional outcome following aseptic single-stage revision knee arthroplasty. Knee Surg Sports Traumatol Arthrosc 2012;20:1994-2001.

53 Baier C, Lüring C, Schaumburger J, et al. Assessing patientoriented results after revision total knee arthroplasty. J Orthop Sci 2013;18:955-61.

54 Huang R, Barrazueta G, Ong A, et al. Revision total knee arthroplasty using metaphyseal sleeves at short-term follow-up. Orthopedics 2014;37:e804-9

55 Kasmire KE, Rasouli MR, Mortazavi SMJ, et al. Predictors of functional outcome after revision total knee arthroplasty following aseptic failure. Knee 2014;21:264-7.

56 Luque R, Rizo B, Urda A, et al. Predictive factors for failure after total knee replacement revision. Int Orthop 2014;38:429-35.

57 Stambough JB, Clohisy JC, Barrack RL, et al. Increased risk of failure following revision total knee replacement in patients aged 55 years and younger. Bone Joint J 2014;96-B:1657-62.

58 Weiss RJ, Thorsell M, Stark A, et al. 2- to 9-year outcome of stemmed total knee arthroplasty. similar failure rates in patients when used primary or as a revision. Acta Orthop 2014;85:609-13.

59 Hitt K, Bhowmik-Stoker M, Howard M, et al. Joint line restoration in a contemporary revision knee system. J Knee Surg 2015;28:75-82.

60 Kim Y-H, Park J-W, Kim J-S, et al. Long-Term clinical outcomes and survivorship of revision total knee arthroplasty with use of a constrained condylar knee prosthesis. J Arthroplasty 2015;30:1804-9.

61 Konrads C, Brieske S, Holder M, et al. Outcome of isolated polyethylene tibial insert exchange after primary cemented total knee arthroplasty. Int Orthop 2015;39:1093-7. 
62 Lunebourg A, Parratte S, Ollivier M, et al. Are revisions of Unicompartmental knee arthroplasties more like a primary or revision TKA? J Arthroplasty 2015;30:1985-9.

63 Grayson CW, Warth LC, Ziemba-Davis MM, et al. Functional Improvement and Expectations Are Diminished in Total Knee Arthroplasty Patients Revised for Flexion Instability Compared to Aseptic Loosening and Infection. J Arthroplasty 2016;31:2241-6.

64 Leta TH, Lygre SHL, Skredderstuen A, et al. Outcomes of Unicompartmental knee arthroplasty after aseptic revision to total knee arthroplasty: a comparative study of 768 TKAs and 578 UKAs revised to TKAs from the Norwegian arthroplasty register (1994 to 2011). J Bone Joint Surg Am 2016;98:431-40.

65 Leta TH, Lygre SHL, Skredderstuen A, et al. Secondary patella resurfacing in painful non-resurfaced total knee arthroplasties : A study of survival and clinical outcome from the Norwegian Arthroplasty Register (1994-2011). Int Orthop 2016;40:715-22.

66 Hamilton DF, Simpson PM, Patton JT, et al. Aseptic revision knee arthroplasty with total stabilizer prostheses achieves similar functional outcomes to primary total knee arthroplasty at 2 years: a longitudinal cohort study. J Arthroplasty 2017;32:1234-40.

67 Lim JBT, Chong HC, Pang HN, et al. Revision total knee arthroplasty for failed high tibial osteotomy and unicompartmental knee arthroplasty have similar patient-reported outcome measures in a two-year follow-up study. Bone Joint J 2017;99-B:1329-34.

68 Martin-Hernandez C, Floria-Arnal LJ, Muniesa-Herrero MP, et al. MidTerm results for metaphyseal sleeves in revision knee surgery. Knee Surg Sports Traumatol Arthrosc 2017;25:3779-85.

69 Rajgopal A, Panjwani TR, Rao A, et al. Are the outcomes of revision knee arthroplasty for flexion instability the same as for other major failure mechanisms? J Arthroplasty 2017;32:3093-7.

70 Sandiford NA, Misur P, Garbuz DS, et al. No difference between trabecular metal cones and femoral head allografts in revision TKA: minimum 5-year followup. Clin Orthop Relat Res 2017;475:118-24.

71 Zhamilov V, Karatosun V, Kalkan S, et al. Evaluation of extensor mechanism in revision knee arthroplasty. J Arthroplasty 2017;32:2484-6.

72 Agarwal S, Neogi DS, Morgan-Jones R. Metaphyseal sleeves in revision total knee arthroplasty: minimum seven-year follow-up study. Knee 2018;25:1299-307.

73 Boelch SP, Arnholdt J, Holzapfel BM, et al. Revision knee arthroplasty with rotating hinge systems in patients with gross ligament instability. Int Orthop 2018;42:2825-33.

74 Gómez-Vallejo J, Albareda-Albareda J, Seral-García B, et al. Revision total knee arthroplasty: hybrid vs standard cemented fixation. $J$ Orthop Traumatol 2018;19:9.
75 Weber M, Renkawitz T, Voellner F, et al. Revision surgery in total joint replacement is Cost-Intensive. Biomed Res Int 2018;2018:1-8.

76 Bin Abd Razak HR, Lee JHM, Tan SM, et al. Satisfaction rates are low following revision total knee arthroplasty in Asians despite improvements in patient-reported outcome measures. J Knee Surg 2020;33:1041-6.

77 Konrads C, Franz A, Hoberg M, et al. Similar outcomes of two-stage revisions for infection and one-stage revisions for aseptic revisions of knee endoprostheses. J Knee Surg 2019;32:897-9.

78 Kurmis AP, Herman A, Mclntyre AR, et al. Pseudotumors and high-grade aseptic Lymphocyte-Dominated vasculitis-associated lesions around total knee replacements identified at aseptic revision surgery: findings of a large-scale histologic review. J Arthroplasty 2019;34:2434-8.

79 Lim JBT, Pang HN, Tay KJD, et al. Clinical outcomes and patient satisfaction following revision of failed unicompartmental knee arthroplasty to total knee arthroplasty are as good as a primary total knee arthroplasty. Knee 2019;26:847-52.

80 Scior W, Chanda D, Graichen H. Are stems redundant in times of metaphyseal sleeve fixation? J Arthroplasty 2019;34:2444-8.

81 Stockwell KD, Malleck S, Gascoyne TC, et al. Clinical and radiographic outcomes of a hybrid fixation revision total knee arthroplasty system at short to mid-term follow-up. Knee 2019;26:240-9.

$82 \mathrm{Klim}$ SM, Amerstorfer F, Bernhardt GA, et al. Excellent mid-term Osseointegration and implant survival using metaphyseal sleeves in revision total knee arthroplasty. Knee Surg Sports Traumatol Arthrosc 2020;28:3843-8.

83 Larsen JB, Mogensen L, Arendt-Nielsen L, et al. Intensive, personalized multimodal rehabilitation in patients with primary or revision total knee arthroplasty: a retrospective cohort study. BMC Sports Sci Med Rehabil 2020;12:5.

84 Oliver G, Jaldin L, Camprubí E, et al. Observational study of total knee arthroplasty in aseptic revision surgery: clinical results. Orthop Surg 2020;12:177-83.

85 Amstutz HC, Thomas BJ, Jinnah R, et al. Treatment of primary osteoarthritis of the hip. A comparison of total joint and surface replacement arthroplasty. J Bone Joint Surg Am 1984;66:228-41.

86 Ware J, Kosinski M, Keller SD. A 12-Item short-form health survey: construction of scales and preliminary tests of reliability and validity. Med Care 1996;34:220-33.

87 Mulhall KJ, Ghomrawi HM, Scully S, et al. Current etiologies and modes of failure in total knee arthroplasty revision. Clin Orthop Relat Res 2006;446:45-50. 